\title{
The Effect of Anemia Free Club Interventions to Improve Knowledge and Attitude of Nutritional Iron Deficiency Anemia Prevention among Adolescent Schoolgirls in Bandar Lampung City, Indonesia
}

\author{
Reni Zuraida $^{1 *}$, Nur Indrawati Lipoeto ${ }^{2 *}$, Masrul Masrul $^{2}$, Judhiastuty Februhartanty ${ }^{3}$ \\ ${ }^{1}$ Doctoral Program, Faculty of Medicine, Universitas Andalas, Padang City, Indonesia, ${ }^{2}$ Department of Nutrition, Faculty \\ of Medicine, Universitas Andalas, Padang City, Indonesia, ${ }^{3}$ SEAMEO REFCON (Regional Centre for Food and Nutrition), \\ Universitas Indonesia, Jakarta City, Indonesia
}

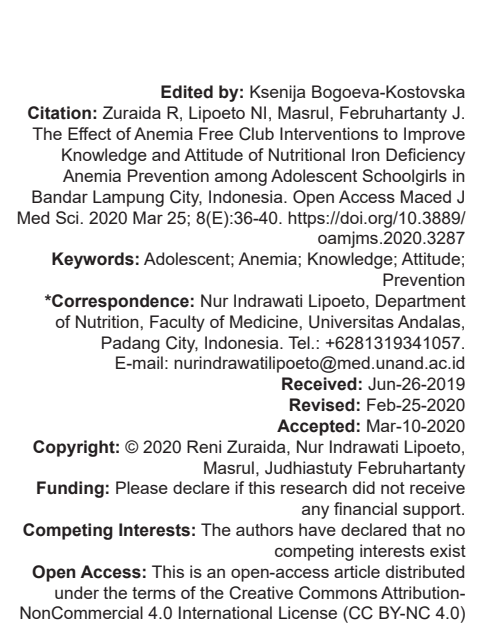

\begin{abstract}
BACKGROUND: Anemia in adolescent is a global public health problem affecting both developing and developed countries. Adolescents are at high risk of anemia. School-based interventions are important to decrease the anemia.

AIM: This study was performed to determine the effect of anemia free club interventions to improve knowledge and attitude of nutritional iron deficiency anemia prevention among adolescent schoolgirls in Bandar Lampung City, Indonesia.

METHODS: The authors conducted a quasi-experimental. The study sample consists of 55 intervention groups and 47 control groups of senior high schoolgirls in Bandar Lampung City. The intervention group attended nutrition education-based, namely, anemia free club sessions for 12 weeks, while the control group did not. The sampling technique is proportional random sampling. Before and after the intervention program, knowledge and attitude questionnaire were filled out for both the groups. A paired sample t-test was used for data analysis. $p<0.05$ was considered as statistically significant effect. Finally, data were collected and analyzed by the SPSS program.
\end{abstract}

RESULTS: This study known before the intervention, there were no significant differences regarding the knowledge and attitude in two groups ( $p>0.05)$. After the intervention, there were significant differences in the levels of knowledge and attitude between intervention and control groups $(p<0.05)$.

CONCLUSION: This analysis confirmed an effect of anemia free club interventions to improve knowledge and attitude of nutritional iron deficiency anemia prevention among adolescent schoolgirls.

\section{Introduction}

Nutritional anemia is one of the global nutritional problems that are prevalent among female adolescents aged 15-19 years [1]. Based on the World Health Organization data, the prevalence of anemia is $29.4 \%$. The Southeast Asia data in 2011 estimated $41.9 \%$ prevalence of anemia. In Indonesia, anemia among adolescent girls is one of the health problems. There are 7.5 million cases of iron deficiency anemia with the prevalence of anemia that is $22.7 \%$ [2]. Lampung is one of the provinces in Indonesia, an estimated $25.9 \%$ prevalence of anemia and higher than the national prevalence [3].

It is very important to run health education programs for women to prevent iron deficiency anemia. It is also important to conduct health education programs for women before marriage. Health education in schools plays a key role in increasing the knowledge and attitudes of the students [4].
The previous study known that there were significant differences in the levels of knowledge and attitude of nutritional iron deficiency anemia prevention among adolescent schoolgirls [5], [6], [7]. However, nutrition education will only affect individuals. In this case, the effect of knowledge about healthy food can support healthy or unhealthy behavior and food preferences [8], [9].

The results of previous studies stated that the eating behavior of young women not only be done through nutrition education but also must be approached to all factors that can influence it. For this reason, reinforcing factors and enabling factors are needed to encourage changes in the good behavior of young women [10].

One of alternative solution for reduces of iron deficiency anemia among adolescent schoolgirls is anemia free club. This intervention needed because it involves three major components that affect adolescent schoolgirls are peer group, teacher, and 
mother (tripartite paradigm). There is no model for treating anemia in adolescent schoolgirls who use the tripartite paradigm and by maximizing the role of mothers as supervisors at home eating and teachers as facilitators. This study was performed to determine the effect of anemia free club interventions to improve knowledge and attitude of nutritional iron deficiency anemia prevention among adolescent schoolgirls in Bandar Lampung City, Indonesia.

\section{Methods}

\section{Study design and research sample}

The authors conducted a quasi-experimental. The study sample consists of 55 intervention groups and 47 control groups of senior high schoolgirls in Bandar Lampung City. The intervention group attended nutrition education-based anemia free club sessions for 12 weeks, while the control group did not. The sampling technique is proportional random sampling. Inclusion criteria were as follows: (a) Menarche, (b) not pregnant, (c) no history of chronic diseases or infections or blood disorders (tuberculosis, malaria, thalassemia, leukemia, and aplastic anemia), (d) not alcohol and/or drugs and smoking consumption, and (e) not taking a similar multivitamin-mineral supplement.

\section{Operational definitions}

The variables of this study included that the independent variable was nutrition educationbased anemia free club and dependent variable was knowledge and attitude of nutritional iron deficiency anemia prevention among adolescent schoolgirls.

\section{Research procedure} on Figure 1.

Research procedure of this study was shown

\section{Data collection technique}

In this study, an informed consent was prepared to protect respondents and researchers when carrying out research. This study was approved by the Ethics Commission of the Faculty of Medicine, Universitas Lampung with No: 4489A/UN26.8/DL/2017. The intervention group attended nutrition educationbased anemia free club sessions for 12 weeks. This model develops the teacher's role in how to provide information regarding the importance of efforts to prevent iron deficiency anemia and monitor adolescent health. Mothers are given information on how to prepare good food containing iron and prepare it based on

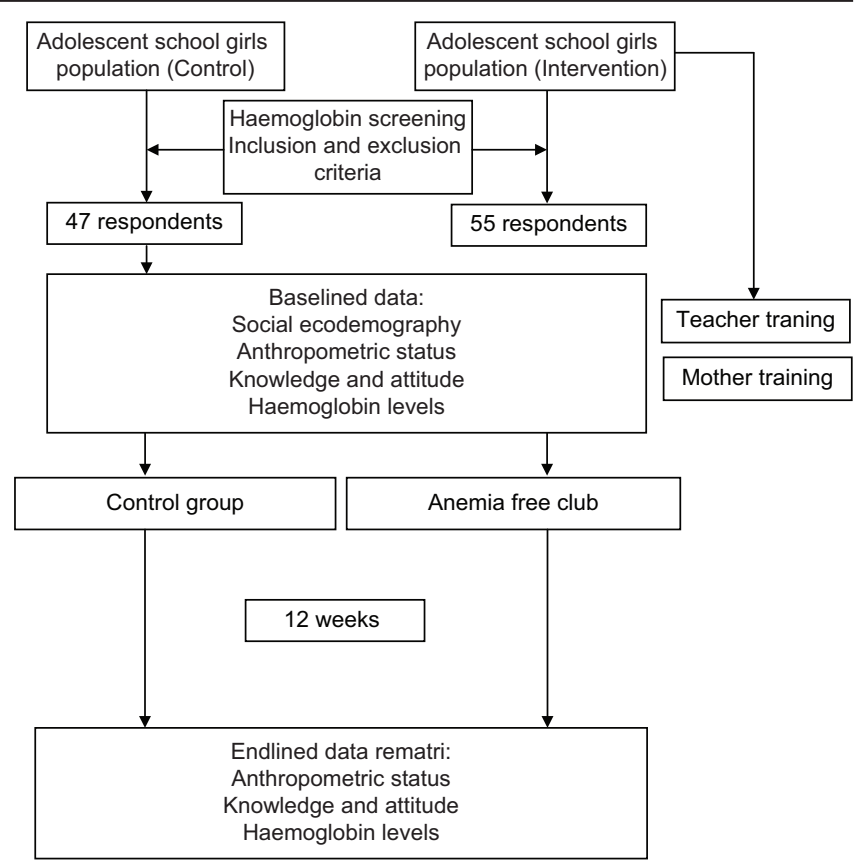

Figure 1: Research procedure

serving sizes, compile menus according to nutritional needs, and assess nutritional status by anthropometric methods (body mass index [BMl]/age). During the 12 weeks of the implementation phase of this model, the teacher was selected and the female adolescent mothers played their respective roles. The teacher as a facilitator and the mother as a companion eat rheumatism at home. Young women will get nutrition education related to efforts to prevent iron deficiency anemia. Before and after the intervention program, knowledge and attitude questionnaire were filled out for both the groups.

\section{Data analysis}

A paired sample t-test was used for data analysis. $p<0.05$ was considered as statistically significant effect. Finally, data were collected and analyzed by the SPSS program.

\section{Results}

Table 1 known that the mean of adolescent girls' age in high school in interventions group was 15.1 years with mean of the menstrual period that was 6.5 days, while the mean of adolescent girls' age in high school in the control group is 15.3 years, and the mean of the menstrual period was 6.4 days. The characteristics of religion and ethnicity in both control and intervention are similar to those dominated by Islam and are dominated by Javanese and Lampung ethnicity. For parental education, most of the father 
Table 1: Characteristic of respondents

\begin{tabular}{lll}
\hline Characteristic & Intervention & Control \\
\hline Age (years), mean (min-max) & $15.1(13.9-16.3)$ & $15.3(14.1-17.0)$ \\
Menstrual period (days), mean (min-max) & $6.5(3.0-12.0)$ & $6.4(3.0-11.0)$ \\
Religion, f (\%) & & \\
Islam & $54(98.18)$ & $43(91.49)$ \\
Christian & $1(1.82)$ & $1(2.13)$ \\
Hinduism & 0 & $3(6.38)$ \\
Ethnicity, $\mathrm{f}(\%)$ & & \\
Javanese & $25(45.45)$ & $22(46.81)$ \\
Lampung & $17(30.91)$ & $14(29.79)$ \\
Palembang & $6(10.91)$ & $2(4.26)$ \\
Sundanese & $3(5.45)$ & $3(6.38)$ \\
Batak & $1(1.82)$ & $2(4.26)$ \\
Bali & 0 & $3(6.38)$ \\
Others & $3(5.45)$ & $1(2.13)$ \\
Father's education, $\mathrm{f}(\%)$ & 0 & $1(2.13)$ \\
Elementary & $19(34.55)$ & $24(51.06)$ \\
Senior high school & $27(49.09)$ & $15(31.91)$ \\
Undergraduate school & $8(14.55)$ & $5(10.64)$ \\
Graduate school & 0 & $1(2.13)$ \\
Doctoral & $1(1.82)$ & $1(2.13)$ \\
Mother's education, $\mathrm{f}(\%)$ & $1(1.82)$ & $1(2.13)$ \\
Elementary & $19(34.55)$ & $21(44.68)$ \\
Junior high school & $26(47.27)$ & $19(40.43)$ \\
Senior high school & $6(10.91)$ & $5(10.64)$ \\
Undergraduate school & & \\
Graduate school & $15(27.27)$ & $15(31.91)$ \\
Father's occupation, $\mathrm{f}(\%)$ & $1(1.82)$ & $1(2.13)$ \\
Civil servant & 0 & $1(2.13)$ \\
Laborer & $1(1.82)$ & $1(2.13)$ \\
Farmer & $2(3.64)$ & $6(12.77)$ \\
Service officer & $30(54.55)$ & $21(44.68)$ \\
Trader & $4(7.27)$ & $2(4.26)$ \\
Entrepreneur & $14(25.45)$ & $12(25.53)$ \\
Others & $27(49.09)$ & $26(55.32)$ \\
Mother's occupation, $\mathrm{f}(\%)$ & $2(3.64)$ & $3(6.38)$ \\
Civil servant & $4(7.27)$ & 0 \\
Housewife & $7(12.73)$ & $6(12.77)$ \\
Trader & 0 & $1(2.13)$ \\
Service officer & $55(100.00)$ & $46(97.87)$ \\
Others & & \\
Family income, $\mathrm{f}(\%)$ & & \\
Low income & & \\
Middle income & & \\
\hline
\end{tabular}

and mother's education in the intervention group is graduate school; a contrast to the control group is high school. The father's occupation is dominated by entrepreneur and civil servant both in two groups. Most of the respondent's mothers were housewives in both two groups. Most family income in the intervention group is in the moderate category ( $>5$ million 10 million rupiah), while in the control group is mostly low (0-5 million rupiah).

Table 2 known less than half of respondents in the intervention and control group had nutritional status based on BMI with classified underweight and normal. Adolescent girls with chronic energy deficiency both in the intervention and control group were similar to $61.82 \%$ and $61.70 \%$. Anemia level respondents with moderate were $25.45 \%$ in the intervention group and 8.52 in the control group.

\section{Table 2: Nutritional status}

\begin{tabular}{lll}
\hline Nutritional status & Intervention & Control \\
\hline Nutritional status (body mass index), $\mathrm{f}(\%)$ & & \\
$\quad$ Underweight & $22(40.00)$ & $17(36.17)$ \\
$\quad$ Normal & $23(41.82)$ & $25(53.19)$ \\
$\quad$ Overweight & $8(14.55)$ & $1(2.13)$ \\
$\quad$ Obese 1 & $1(1.82)$ & $4(8.51)$ \\
$\quad$ Obese 2 & $1(1.82)$ & 0 \\
Chronic energy deficiency, $\mathrm{f}(\%)$ & $34(61.82)$ & $29(61.70)$ \\
$\quad$ Chronic energy deficiency & $21(38.18)$ & $18(38.30)$ \\
$\quad$ Normal & & \\
Anemia level & $14(25.45)$ & $4(8.51)$ \\
$\quad$ Moderate $(\mathrm{Hb}: 8.0-10.0 \mathrm{~g} / \mathrm{dl}), \mathrm{f}(\%)$ & $41(74.55)$ & $43(91.49)$ \\
$\quad$ Low (Hb: $10.1-119 \mathrm{~g} / \mathrm{dl}), \mathrm{f}(\%)$ & &
\end{tabular}

The effect of anemia free club interventions to improve knowledge and attitude of nutritional iron deficiency anemia prevention among adolescent schoolgirls (Tables 3 and 4).

Table 3: Mean score difference of knowledge and attitude between intervention and control group before and after the intervention

\begin{tabular}{lllll}
\hline Variables & Score & Intervention & Control & p-value \\
\hline Knowledge & Pre-test & 44.80 & 41.53 & 0.107 \\
& Post-test & 79.65 & 44.37 & $<0.001^{*}$ \\
Attitude & Pre-test & 66.49 & 65.38 & 0.327 \\
& Post-test & 69.76 & 67.13 & $0.019^{* *}$ \\
\hline${ }^{*}$ Significant, $p<0.001,{ }^{*}$ * significant, $p<0.05$ & & &
\end{tabular}

Table 3 known that there were no significant differences of knowledge and attitude scores in both groups before intervention $(p>0.05)$. However, there were significant differences between knowledge and attitude scores in both groups after intervention.

Table 4 known after the intervention, there were significant differences in the levels of knowledge and attitude between intervention and control groups $(p<0.05)$.

Table 4: Mean score difference of knowledge and attitude between intervention and control group

\begin{tabular}{|c|c|c|c|c|c|c|c|c|}
\hline \multirow[t]{2}{*}{ Variables } & \multicolumn{4}{|c|}{ Intervention } & \multicolumn{4}{|c|}{ Control } \\
\hline & Pre & Post & $\Delta$ & $p$ & Pre & Post & $\Delta$ & $p$ \\
\hline \multicolumn{9}{|l|}{ Knowledge } \\
\hline Mean & 44.80 & 79.65 & 34.85 & $<0.001^{*}$ & 41.53 & 44.37 & 2.84 & 0.106 \\
\hline Minimum & 24.25 & 52.00 & & & 16.00 & 23.70 & & \\
\hline Maximum & 67.75 & 100.00 & & & 59.25 & 74.66 & & \\
\hline \multicolumn{9}{|l|}{ Attitude } \\
\hline Mean & 66.49 & 69.76 & 3.27 & $<0.001^{*}$ & 65.38 & 67.13 & 1.74 & $0.018^{\star \star}$ \\
\hline Minimum & 55.00 & 56.00 & & & 51.00 & 48.00 & & \\
\hline Maximum & 81.00 & 85.00 & & & 81.00 & 82.00 & & \\
\hline
\end{tabular}

Boxplot score difference of knowledge and attitude between intervention and control group is shown in Figures 2 and 3.

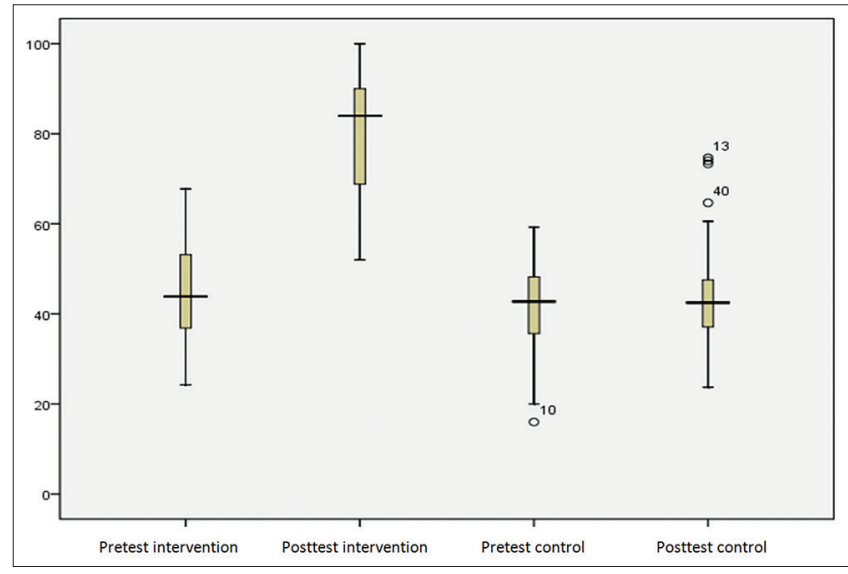

Figure 2: Boxplot score difference of knowledge between intervention and control group

\section{Discussion}

In this study known, there were significant differences in the levels of knowledge and attitude between intervention and control groups. The previous study found that the nutritional education approach given to students through empowering teachers in schools 


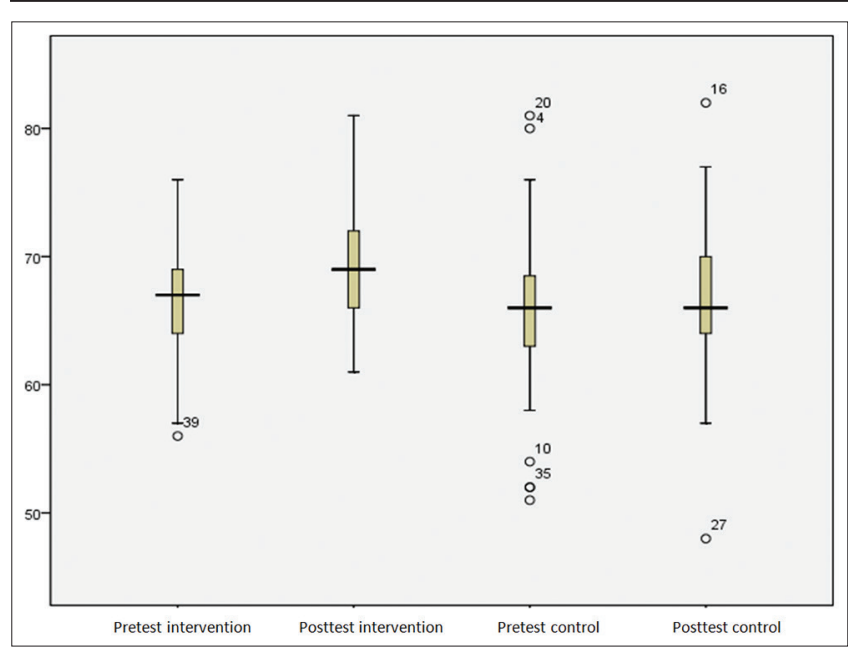

Figure 3: Boxplot score difference of attitude between intervention and control group

could change the aspects of students' knowledge and attitude in a positive direction [11]. Another study revealed that appropriate nutrition education interventions can change nutrition and good lifestyle behaviors [12]. The study also stated that nutritional interventions in the form of nutrition education and healthy eating promotion and proper healthy lifestyles can increase the consumption of vegetables and fruits, after they know and understand the benefits.

Nutrition education in schools is one of the efforts to achieve the goal of nutrition conscious families [13]. Therefore, adolescent students in schools are family members who need to get proper information about nutrition [11]. In this study, in the implementation of the anemia free club, the teacher provided nutritional education to anemia female students using the nutrition education module, which motivated teachers in secondary schools to deliver the nutrition material to their students. In addition, the different learning methods each week are a trick so that rematerializes are not bored in participating in the program for 12 weeks.

Nutrition education is still very much needed by adolescents at the formal education level, as an entry point for improving the knowledge, attitudes, and nutritional behavior of adolescent students toward achieving balanced nutrition behavior and preventing anemia on adolescent girls. This is in line with the Ministry of Health's priority goals in improving public health, one of which is by improving community nutrition through the national awareness movement nutrition conscious family which is pursued on the basis of community empowerment itself, including empowering teachers as educators in schools. It is necessary to use teaching materials and media tools for counseling or learning about nutrition in schools in accordance with nutrition education standards. The use of more diverse intervention media will increase the knowledge score of the intervention group compared to the use of print media only [14]. The previous studies found, where nutrition education significantly increases awareness, attitudes, and behaviors to prevent anemia [6], [7].

Overall, nutrition education for students in schools related to anemia programs through teacher empowerment has good potential to change healthy lifestyles with balanced nutrition in teenagers in Indonesia. Therefore, it is strongly recommended that the learning and delivery of material about anemia and nutrition in high school need to contain the right message and update according to the knowledge needs for repatriates.

\section{Conclusion}

This analysis confirmed an effect of anemia free club interventions to improve knowledge and attitude of nutritional iron deficiency anemia prevention among adolescent schoolgirls. The results of this study recommend the need to reduce iron deficiency anemia with by implementing anemia free club interventions which treating anemia in adolescent schoolgirls by maximizing the role of mothers as supervisors at home eating and teachers as facilitators.

\section{Acknowledgments}

The authors would like to thank all staff of the Doctoral Program Faculty of Medicine, Universitas Andalas, Padang City, Indonesia, and all respondents in this study.

\section{References}

1. Angadi N, Ranjitha A. Knowledge attitude and practice about anemia among adolescent girls in urban slums of Davangere city Karnataka. Int J Med Sci Public Health. 2014;5:416-9. https://doi.org/10.5455/ijmsph.2016.2007201570

2. World Health Organization. Guideline:Daily iron Supplementation in Adult Women and Adolescent Girls. Geneva: World Health Organization; 2016. Available from: http://www.who.int/iris/ handle/10665/204761. [Last accessed on 2019 May 22]

3. Ministry of Health Republic of Indonesia. Basic Health Research in Indonesia. Jakarta: Ministry of Health Republic of Indonesia; 2013. https://doi.org/10.25133/jpssv27n1.003

4. Shojaeizadeh D. A study on knowledge attitude and practice of secondary school girls in Qazvin on iron deficiency anemia. Iran J Public Health. 2001;30:53-6.

5. Sadeghifar J, Hasan J, Ahmad P, Shahla R, Sorayya A Ramin $\mathrm{M}$, et al. Educational intervention on knowledge, attitude and practice (KAP) on girl students (high school) in Baneh city about Iron deficiency anemia. Jentashapir J Health Sci. 


\section{2;4:39-46.}

6. Mansourian M, Shafieyan Z, Qorbani M, Bazraki HR, Charkazi A Asayesh $\mathrm{H}$, et al. Effect of nutritional education based on HBM model on anemia in golestan girl guidance school students. J Health Educ Health Promot. 2013;1:49-54.

7. Ghaderi N, Ahmadpour M, Saniee N, Karimi F, Ghaderi C, Mirzaei $\mathrm{H}$. Effect of education based on the health belief model (HBM) on anemia preventive behaviors among Iranian girl students. Int J Pediatr. 2017;5:5043-52.

8. Di Noia J, Byrd-Bredbenner C. Adolescent fruit and vegetable intake: Influence of family support and moderation by home availability of relationships with afrocentric values and taste preferences. J Acad Nutr Diet. 2013;113(6):803-8. https://doi. org/10.1016/j.jand.2013.02.001

PMid:23545060

9. Spronk I, Kullen C, Burdon C, O'Connor H. Relationship between nutrition knowledge and dietary intake. $\mathrm{Br} J$ Nutr. $\quad 2014 ; 111(10): 1713-26 . \quad$ https://doi.org/10.1017/ s0007114514000087

PMid:24621991
10. Green LW, Kreuter MW. Health Promotion Planning: An Aducational and Environmental Approach. $2^{\text {nd }}$ ed. London: Mayfield Publishing Company; 1991.

11. Contento I. Nutrition Education: Linking Research, Theory, and Practice. $2^{\text {nd }}$ ed. Burlington: Jones and Bartlett Learning; 2011.

12. Young DR, Steckler A, Cohen S, Pratt C, Felton G, Moe SG, et al Process evaluation results from a school-and community-linked intervention: The trial of activity for adolescent girls (TAAG). Health Educ Res. 2008;23(6):976-86. https://doi.org/10.1093/ her/cyn029

PMid:18559401

13. Ministry of Health Republic of Indonesia. Basic Health Research in Indonesia. Jakarta: Ministry of Health Republic of Indonesia; 2016. https://doi.org/10.25133/jpssv27n1.003

14. Upadhyay S, Kumar AR, Raghuvanshi RS, Singh BB. Impact of nutrition education on knowledge and haemoglobin status of hill women in Uttarakhand State of India. Malays $\mathrm{J}$ Nutr. 2011;17(3):347-57.

PMid:22655456 